\title{
Editorial
}

\section{Nightingale's message for today's nurses}

\author{
Jozsef Betlehem \\ University of Pécs, Faculty of Health Sciences, Pécs, Hungary
}

"I am of certain convinced that the greatest heroes are those who do their duty in the daily grind of domestic affairs whilst the world whirls as a maddening dreidel." (Florence Nightingale)

Florence Nightingale was born in 1820, so throughout her bicentenary year in 2020 there will be a series of memorial events to internationally celebrate this important date. She is remembered as the founder of modern nursing in the 19th century, but in her own lifetime she was more influential within healthcare systems, an iconic leader of nurses and a famous advocate of nursing. Based on nurses' experience in the hospitals, she was able to draw conclusions and define general rules for nursing in order to lay down basic principles of nursing science. Her work was not only acknowledged in Europe but also worldwide. Her essential principles on disease prevention and experimental fieldwork still live on today. Her views regarding the structured and regulated work that focuses on patient-centralized care are even more vivid now than before.

Nightingale's heritage will be globally reflected in many ways. The World Health Organisation has declared 2020 as the Year of the Nurse and Midwife (WHO, 2020a). This is a very promising opportunity to put nurses, midwives and other allied health care professionals at the centre of global and national health policy - and to demonstrate how these occupations can affect the health of the population. Nursing associations might join this initiative, highlighting the power of nurses in their country and implementing different actions. Beside this, the 'Nursing Now' campaign is a collaboration between the World Health Organisation and the International Council of Nurses (2020) which will aim to improve global health by raising the status and profile of nursing in different societies (WHO, 2020b). Other national associations of nurses will commemorate the achievements of Nightingale with different programmes throughout year.

All around the world, Nightingale's name has been synonymous with highlighting the challenges of nursing and fighting for nurses' rights. The Nightingale 2020 Conference organized by the Florence Nightingale Foundation and held in the ExCeL exhibition and conference centre in London this October became a symbolic event. Due to the current development of the coronavirus pandemic, United Kingdom (UK) authorities decided to name a new field hospital after Nightingale - and this hospital was established at the beginning of April this year.
The National Health Service (NHS) Nightingale Hospital in London was the first of a number of field hospitals across the UK. The first of the government's emergency field hospitals to treat coronavirus patients was transformed into a hospital in just nine days. The temporary NHS Nightingale Hospital can hold as many as 4,000 patients who might need intensive care beds and artificial ventilation. The Nightingale hospital initially has 500 beds in place, with space for another 3,500. Staff will be recruited from across the UK, including student nurses, medical students who will start working earlier, and other health care personnel who will come out of retirement (BBC, 2020).

In her active years and during the Crimean War (18531856), Florence Nightingale used innovation and data to change patient care, improve health outcomes and professionalise nursing. She recognized that more soldiers were dying from infectious disease than from injuries acquired in battles. Nightingale and her crew of nurses effectively improved the unsanitary conditions at a British base hospital in Scutari, working night and day to reduce the death count by two thirds. Although this war belongs to history, the message is clear. Nursing and caring for sick people always plays an essential and significant role in treating patients successfully. The new field hospital in London is evidence of how Nightingale's legacy continues to inspire and motivate health care decision makers and nurses around the world. Her century-old visionary work exists in contemporary hospitals and in other health services through the way nursing practice has been shaped.

"It may seem a strange principle to enunciate as the very first requirement in a Hospital that it should do the sick no harm." (Nightingale, 1946)

Today's battle is not yet won. The great invisible enemy coronavirus - is causing COVID-19 and threatening the population of the world. Nurses must stand on the frontlines to treat patients and prevent its spread. As the situation escalates, nurses will have to face more and more conflicts regarding the lack of efficient resources and state-of-the-art care for patients. This COVID-19 pandemic brings to the forefront the ethical issues in nursing, and legal responsibilities with respect to how far nurses can sacrifice themselves in order to care for critically ill and infectious patients. They have to balance their own and their families' health with that of the victims they are

\footnotetext{
* Author for correspondence: Jozsef Betlehem, University of Pecs, Faculty of Health Sciences, H-7621 Pécs, Vörösmarty Street 4, Hungary; e-mail: betlehem@etk.pte.hu http://doi.org/10.32725/kont.2020.015

Submitted: 2020-04-15 • Accepted: 2020-04-27 • Prepublished online: 2020-04-30 
caring for. Communities and employees must see and accept the physical limitations of frontline health care workers and provide them with sufficient backing in terms of personal protective equipment, and social and mental support (American Nurses Association, 2020).

"No global health agenda can be realized without concerted and sustained efforts to maximize the contributions of the nursing workforce and their roles within interprofessional health teams." (WHO, 2020b)

This statement emphasizes the real value of the nursing workforce envisaged by WHO, ICN and the Nursing Now campaign. We very much hope to see the everyday results of this majestic statement in health policies and in fostering the wellbeing of nurses, too.

Nightingale paid much attention to advocating for nursing during her life - something which was neither obvious nor accepted at that time (Selanders and Crane, 2012). These days we should not forget her message that nursing should be recognised as an essential part of the health care system and that nurses must receive the education this work demands. In terms of patient care, the technical environment, medical technology and evidence-based knowledge has changed tremendously. Therefore the new roles of nurses must be recognized and supported in order to fulfil Nightingale's wishes.

\section{References}

1. American Nurses Association (2020). Nurses, ethics and the response to the COVID-19 pandemic. [online] [cit. 2020-0409]. Available at: https://www.nursingworld.org/ 495c6c/ globalassets/practiceandpolicy/work-environment/health-safety/coronavirus/nurses-ethics-and-the-response-to-thecovid-19-pandemic.pdf

2. BBC - British Broadcasting Corporation (2020). Coronavirus: How NHS Nightingale was built in just nine days. [online] [cit. 2020-04-09]. Available at: https://www.bbc.com/news/ health-52125059

3. ICN - International Council of Nurses (2020). Nursing Now campaign. [online] [cit. 2020-04-09]. Available at: https://www. icn.ch/what-we-do/campaigns/nursing-now

4. Nightingale F (1946). Notes on Nursing: What Nursing Is, What Nursing is Not. Philadelphia, London, Montreal: J. B. Lippincott Co. 1946 Reprint. First published London, 1859: Harrison \& Sons.

5. Selanders L, Crane P (2012). The voice of Florence Nightingale on advocacy. Online J Issues Nurs 17(1): 1.

6. WHO - World Health Organization (2020a). Year of the Nurse and the Midwife 2020. [online] [cit. 2020-04-09]. Available at: https://www.who.int/news-room/campaigns/year-of-the-nurseand-the-midwife-2020

7. WHO - World Health Organization (2020b). State of the world's nursing 2020: investing in education, jobs and leadership. Geneva. [online] [cit. 2020-04-09]. Available at: https://apps.who.int/iris/bitstream/hand le/10665/331673/9789240003293-eng.pdf 